\title{
FORMAÇÃO DE ASSENTAMENTOS PRECÁRIOS A PARTIR DAS OCUPAÇÕES DE TERRAS E DA AUTOCONSTRUÇÃO - UM OLHAR PARA SANTA RITA, VILA VELHA/ES
}

\author{
Andreia Fernandes Muniz ${ }^{1}$, Larissa Letícia Andara Ramos², Ana Paula Rabello Lyra ${ }^{3}$
}

\begin{abstract}
${ }^{1}$ Professora Mestra do curso de graduação em Arquitetura e Urbanismo da Universidade Vila Velha (UVV) e doutoranda do Programa de Pós-graduação em Geografia da Universidade Federal do Espírito Santo (UFES), Email: afernandesmuniz@gmail.com; orcid.org/0000-0001-6764-2225

2 Professora Doutora do Mestrado em Arquitetura e Cidade da Universidade Vila Velha (UVV), Email: larissa.ramos@uvv.br; orcid.org/0000-0002-2295-8995

${ }^{3}$ Professora Doutora do Mestrado em Arquitetura e Cidade da Universidade Vila Velha (UVV), Email: ana.lyra@uvv.br; orcid.org/0000-0003-0806-911X
\end{abstract}

Artigo recebido em 14/06/2020 e aceito em 13/02/2021

\begin{abstract}
RESUMO
Este artigo busca refletir sobre a formação de assentamentos urbanos informais, surgidos a partir do fenômeno das "invasões" de terras que se materializaram pelo país em grande escala no final da década de 70. Para isso, utiliza como recorte empírico de investigação o bairro Santa Rita, localizado no município de Vila Velha no estado do Espírito Santo, analisado sob a perspectiva histórica e atual das transformações que consolidaram o seu território. A metodologia se apropria de revisão da literatura e pesquisa de campo com resultados que demonstram a relação do Poder Público, através das suas ações de provisão de serviços urbanos de infraestrutura e habitação, com a continuidade da formação dos assentamentos precários.
\end{abstract}

Palavras-chave: assentamento informal, autoconstrução, políticas públicas.

\section{INFORMAL SETTLEMENTS FROM LAND USE OCCUPATIONS AND SELF BUILDING PRACTICES. AN OVERVIEW AT SANTA RITA SETTLEMENT, VILA VELHA, ES}

\begin{abstract}
This paper aims to reflect about the informal settlements formation that emerged from the land invasions that were spread all over the country throughout the late seventies. The Santa Rita settlement was selected as the empirical object of this study. It is located in the municipality of Vila Velha in the State of Espírito Santo, northeast of Brazil. It was analyzed by its historical foreground and background transformations that drawn the consolidation of its current grounds. The methodology used the literature review along with the field research to demonstrate the influence of public administration in such recurrent settlements. Study findings suggests that the urban services provided by local administrations lucks in infrastructure and housing effective actions.
\end{abstract}

Keywords: Informal settlement; self-building; public policies. 


\title{
FORMACIÓN DE ASENTAMIENTOS PRECARIOS A PARTIR DE OCUPACIONES TERRESTRES Y AUTOCONSTRUCCIÓN - ESTUDIO DE CASO EN EL BARRIO DE SANTA RITA, CIUDAD DE VILA VELHA / ES, BRASIL
}

\begin{abstract}
RESUMEN
Este artículo reflexiona sobre la formación de asentamientos urbanos informales, que surgieron del fenómeno de las "invasiones" de tierras que se materializaron en todo Brasil a gran escala a fines de la década de 1970. Barrio Santa Rita, ubicado en el municipio de Vila Velha/ES - Brasil, es analizado desde la perspectiva histórica y actual de las transformaciones que consolidaron su territorio. La metodología se apropia de una revisión bibliográfica e investigación de campo con resultados que demuestran la relación del Poder Público, a través de sus acciones para brindar infraestructura urbana y servicios habitacionales, con la continua formación de asentamientos precarios.
\end{abstract}

Palabras-clave: asentamiento informal; autoconstrucción; políticas públicas.

\section{INTRODUÇÃO}

Este trabalho pretende discutir a produção do espaço urbano através da formação dos assentamentos urbanos informais e precários reproduzidos a partir das ocupações de terras que aconteceram no país, principalmente a partir do final da década de 1970, marcada por um acelerado e desordenado processo de urbanização das cidades brasileiras. Em 1960, 45\% da população do país era urbana. Percentual que subiu para 57\% em 1970 com cerca de 52,9 milhões de pessoas, número acrescido em 29,1 milhões em 1980, com 68,9\% da população brasileira (aproximadamente 82 milhões) vivendo em cidades, de um total de 119,10 milhões de habitantes (SANTOS, 2018, p. 32).

O fenômeno do crescimento desordenado das populações urbanas no país após a $2^{\mathrm{a}}$ guerra mundial é consequência da expansão da atividade industrial, do crescimento vegetativo da população, da estagnação da economia agrário exportadora e da precarização do trabalho no campo, que empurrou migrações de trabalhadores para as cidades, em busca de oportunidades de emprego e melhor qualidade de vida.

O crescente processo de urbanização impactou a demanda por terra e moradia, em especial nas regiões metropolitanas. O padrão de ocupação do solo urbano se materializou em assentamentos precários, expressos em favelas e loteamentos irregulares ou clandestinos, provenientes de invasões de terrenos vazios públicos ou privados e de áreas de mangues, alagadiças e de encostas, onde a autoconstrução se reproduziu como forma de morar de grande parte da população de baixo rendimento, excluída pelas políticas públicas sociais.

Sobre o uso do termo invasão neste artigo, cabe ressaltar que ele foi amplamente utilizado pela imprensa nas décadas de 1970 e 1980. Porém, os movimentos sociais de luta por moradia não 
acham o termo apropriado, tendo em vista que o conceito de ocupação é mais adequado, dando legitimidade ao ato de ocupar. O conceito de invasão está associado a um ato ilegítimo, hostil, que se apropria à força de um espaço utilizado por outros, desrespeitando não somente a lei, mas a regras implícitas de convívio humano. Ocupar refere-se a dar utilidade a algo, a um espaço que está sem uso, que descumpre a sua função social (LOURENÇO, 2014, p. 31). Portanto, neste trabalho o termo invasão será substituído por ocupação em alguns momentos e utilizado entre aspas em outros, por respeito e por compreender ser mais apropriado e coerente com a luta pela função social da propriedade.

No final da década de 1970, em meio à decadência do Regime Militar, as ocupações coletivas de terras se multiplicaram em várias regiões do país, realizadas por pequenos grupos ou famílias individuais ou como organização de massa; refletindo a precariedade urbana e habitacional do país.

A luta pela terra se tornou pauta de reivindicação dos trabalhadores mais pobres que viram nas ocupações a solução para morar, em meio a um cenário de grave crise econômica, com rebaixamento dos salários, corroídos pela alta inflação que assolava o país. Excluídos da política habitacional do BNH (Banco Nacional de Habitação) que privilegiou as camadas de poder aquisitivo médio e alto, restou aos mais pobres, impossibilitados de pagar aluguéis, autoconstruir a casa própria em áreas desprovidas de qualquer infraestrutura ou até impróprias para a edificação. O que reflete um total rebaixamento da condição de moradia da população pobre (BONDUKI, 1994, p.141).

Sobre esse panorama, para a sua compreensão é apropriado refletir com o conceito de espoliação urbana de Kowarick (2000, p. 107):

A espoliação urbana só pode ser entendida como produção histórica que, ao se alimentar de um sentimento coletivo de exclusão, produz uma percepção de que algo - um bem material ou cultural - está faltando e é socialmente necessário. Dessa forma, a noção contém a ideia de que o processo espoliativo resulta de uma somatória de extorsões, isto é, retirar ou deixar de fornecer a um grupo, categoria ou classe o que estes consideram como direitos seus.

Espoliados do acesso à moradia adequada por um conjunto de fatores de caráter social, político e econômico, restou aos migrantes do meio rural e às famílias que buscavam fugir do aluguel as “invasões” de terras, modo mais comum de provisão informal da habitação a partir da década de 1950 em países em desenvolvimento, com expansão anual de $15 \%$ a $20 \%$ do fenômeno até a metade da década de 1970 (WERNA et al., 2001, p. 56).

O modo informal ou não-convencional de prover moradia ocorre devido à impossibilidade dos grupos sociais de baixa renda de adquirir uma habitação no mercado formal. Além disso, a produção pública não realizada de forma efetiva é mais um atributo para a exclusão dos mais pobres. 
Sobre o Estado, agente que desempenha um importante papel na conformação do espaço urbano, ele é forçado a tolerar e acomodar um certo grau de ilegalidade e irregularidade na questão da moradia (WERNA et al., 2001, p. 55).

Werna et al. (2001, p. 48) enfatiza que "a chave para compreender os processos envolvidos na incorporação de terras e de imóveis, incluindo a habitação, é a relação entre os interesses, as estratégias e as ações dos agentes envolvidos e a estrutura socioeconômica e política."

Neste contexto, analisar a atuação do Estado é fundamental na formação dos assentamentos informais e precários, tendo em vista que é o ente público responsável pela implementação dos serviços urbanos, que valorizam e consolidam áreas que nasceram da ocupação informal, onde a autoconstrução se reproduz como forma de produção da moradia, modalidade de acesso à casa própria aceita pelo Estado e pelos excluídos de direitos sociais fundamentais. Sobre isso, é pertinente refletir com Kowarick (2009, p. 212):

\begin{abstract}
A casa autoconstruída constitui a única forma de poupança, na medida em que os gastos com aluguel representam um dispêndio que não leva ao acúmulo de bens. Além disso, representam uma forma de habitar instável que requer, no mais das vezes, constantes mudanças. Se a autoconstrução é desgastante, ao menos, perante outras alternativas habitacionais, ela redunda em uma propriedade que, além das vantagens já mencionadas, deixa de ter dispêndios uma vez concluída, tende a valorizar-se na medida em que serviços públicos e privados atingem o bairro onde está situada e, em consequência, representa um pecúlio que uma família pobre dificilmente conseguiria obter se permanecesse na condição de inquilinato.
\end{abstract}

Corrêa (1989, p. 30) ao descrever a atuação dos agentes modeladores do espaço urbano capitalista, enfatiza que os grupos sociais excluídos de bens e serviços, em especial do acesso à habitação seja pela compra ou pelo aluguel, têm como possibilidades de moradia o cortiço, a autoconstrução produzida em loteamentos periféricos, os conjuntos habitacionais produzidos pelo Estado e a favela. Os excluídos tornam-se efetivamente agentes modeladores do espaço urbano, produzindo seu próprio espaço, na produção da favela, em terrenos públicos ou privados invadidos; na maioria dos casos independentemente. A produção deste espaço é uma forma de resistência e ao mesmo tempo uma estratégia de sobrevivência.

Tendo como premissas estes aspectos teórico-conceituais iniciais, este trabalho busca refletir sobre a formação de assentamentos precários urbanos para moradia, surgidos a partir do fenômeno das "invasões" de terras que se materializaram pelo país em grande escala no final da década de 1970. A questão central da discussão é a atuação do Poder Público, suas propostas e ações na provisão de serviços urbanos de infraestrutura e habitação. 
A análise tem como recorte empírico de investigação o bairro Santa Rita de Cássia, localizado no município de Vila Velha, um dos sete municípios que compõe a Região Metropolitana da Grande Vitória, estado do Espírito Santo.

A pesquisa parte da investigação histórica sobre o processo de formação do bairro a partir das ocupações de terras, que mobilizaram os entes municipal e estadual na elaboração de planos e projetos para realizar melhorias e intervenções urbanísticas que dessem melhor qualidade de vida aos moradores. Em seguida, a pesquisa situa o bairro no cenário contemporâneo, com suas transformações e aspectos que o consolidaram como território onde o Poder Público é ausente e onde as "invasões" de terras continuam acontecendo.

Nesse aspecto de continuidade do fenômeno da ocupação irregular, a investigação foi realizada tendo como objeto de estudo um assentamento informal formado sobre uma gleba pública, onde os ocupantes reivindicam a regularização fundiária e autoconstroem suas moradias, conformando um cenário precário de habitar.

Os aspectos essenciais da pesquisa são: compreender a atuação do poder público municipal na questão e suas relações com os agentes excluídos, assim como caracterizar a precariedade do morar na ocupação.

A pesquisa norteia-se pela revisão da literatura, pela coleta de dados em documentos governamentais e reportagens de jornais antigos disponíveis na biblioteca digital do Instituto Jones dos Santos Neves (IJSN), pela pesquisa de campo através de visitas à Prefeitura Municipal de Vila Velha (PMVV) para entender a situação do assentamento precário e visita ao território ocupado para coletar dados sobre uso e ocupação do solo e caracterização das moradias. Como ferramenta complementar foi utilizado o Google Earth Pro.

A investigação sobre a área foi organizada da seguinte forma: em um primeiro momento foi realizada uma visita à prefeitura para conversar com técnicos do poder público envolvidos com as demandas dos ocupantes da área; posteriormente foi realizada uma visita de campo em companhia de um representante do poder público, um líder comunitário da Região da Grande Santa Rita e alguns moradores locais. As duas etapas permitiram compreender os problemas das famílias, as reivindicações, as ações do ente municipal e o modelo de ocupação do solo adotado pelas famílias.

Os resultados, expressos através de mapas, tabelas e iconografia demonstram que a ausência de políticas públicas sociais, em especial às relacionadas à questão fundiária e habitacional, excluíram os mais pobres para áreas precárias de infraestrutura e serviços públicos, com consequências graves 
que permanecem até a atualidade: presença de elevado grau de criminalidade, a continuidade do fenômeno das ocupações de terras, a precariedade das moradias autoconstruídas e a ausência de espaços livres de uso público. O bairro Santa Rita ainda está em transformação, o que demonstra um caráter de exclusão permanente.

\section{ILHA DE SANTA RITA: DAS OCUPAÇÕES DE TERRAS À ACEITAÇÃO DA HABITAÇÃO AUTOCONSTRUÍDA}

A Região da Grande Vitória (RGV), composta na década de 1970 por cinco municípios (Vitória, Vila Velha, Cariacica, Serra e Viana), passou por um processo de adensamento populacional e ampliação da sua mancha urbana, consequências da política de erradicação dos cafezais e da política de desenvolvimento econômico do governo federal para cidades de porte médio.

Durante a década de 1960, em virtude da queda acentuada do preço do café no mercado mundial ocasionado pela alta oferta do produto no mercado externo e pela baixa competitividade do café capixaba frente à sua baixa qualidade, o governo federal incentivou a erradicação dos cafezais por meio de uma política de incentivo aos produtores com o pagamento de indenizações. A erradicação aconteceu em dois períodos: julho de 1962 a julho de 1966 e agosto de 1966 a maio de 1967. Outros fatores, associados à política de desenvolvimento econômico e à industrialização também contribuíram para o contexto das migrações para a RGV na década de 1970 (SIQUEIRA, 2010, p. 48).

Vitória, a capital capixaba, recebeu a maioria dos investimentos e concentrou importantes (projetos industriais, empresas de mineração, siderurgia e celulose) que atraíram um contingente de migrantes vindos dos antigos cafezais e de outros estados. Porém, a indústria não absorveu este grande número de trabalhadores pouco qualificados que buscaram ocupação no comércio ou em atividades informais.

Em 1980 a RGV concentrava 706.263 pessoas, sendo 47,9\% carentes. Uma elevação de 83\% em relação a 1970, quando a população era de 385.998 habitantes (SIQUEIRA, 2010, p. 101). Na década de 1980, das 532.079 pessoas economicamente ativas na RGV, 33,3\% tinham rendimento médio de até 2 salários mínimos; 6,3\% dos trabalhadores recebiam de 3 a 5 salários e apenas 4,7\% tinham ganhos entre 5 e 10 salários. Portanto, 44,7\% não possuíam nenhum rendimento (SIQUEIRA, 2010, p. 133). Esses fatores, somados à ausência de políticas sociais efetivas, provocaram uma série de transformações espaciais em relação à ocupação e distribuição destas pessoas pelo território, que 
excluídas economicamente do acesso à moradia pelo aluguel ou pela compra, buscaram na ocupação ilegal de terrenos em encostas, mangues e alagadiços a forma de autoconstruir a casa própria.

O município de Vila Velha, o mais próximo à Vitória, também sofreu os impactos da aceleração do crescimento populacional, o que teve consequências na configuração do seu espaço urbano. Em 1960 o município, que até então havia tido um crescimento lento e pouco significativo, tinha 56.445 habitantes, número ampliado para 123.742 em 1970, chegando a 203.406 habitantes em 1980, com 50,6\% da sua população sendo carente (103.080 habitantes) (SIQUEIRA, 2010, p. 124).

Ainda durante a década de 1960, Vila Velha possuía o maior número de bairros e a maior população do estado, apresentando também uma aceleração em seu crescimento estimulado pela conclusão das obras da Rodovia Carlos Lindemberg, que ligaria o município à capital Vitória. Nas regiões limítrofes à rodovia, que funcionou como um eixo de expansão, surgiram diversos bairros, formados a partir de loteamentos regulares e ocupações clandestinas (VILA VELHA, 2015, p. 17).

Na década de 1970 a migração para o município aumentou. A ocupação da cidade ocorreu sem controle, de modo que a população migrante passou a ocupar locais inadequados para moradia, como morros, mangues e áreas naturais, contribuindo para a formação da periferia. As oportunidades de emprego nas indústrias, motivo pelo qual muitos migrantes se deslocaram para Vila Velha, não foram suficientes para absorver a mão-de-obra disponível (VILA VELHA, 2015, p.19). Na década seguinte, Vila Velha passou a abrigar 203.401 habitantes $(28,8 \%$ da população da RGV) com 86.140 pessoas morando em 26 assentamentos informais precários, de um total de 82 assentamentos existentes na RGV (SIQUEIRA, 2010, p. 134).

Neste cenário de extrema precariedade e miséria, situa-se o bairro Santa Rita de Cássia, que possui a formação do seu território marcado por um intenso processo de ocupação sobre o mangue, que posteriormente foi aterrado para receber a regularização do traçado dos lotes inicialmente demarcados pela população que o ocupou. $\mathrm{O}$ assentamento espontâneo precário que se formou às margens do Canal do Rio Aribiri reflete a exclusão dos mais pobres, que foram expostos a condições sub-humanas de moradia sobre a forma de palafitas que se reproduziram sobre uma área de grande riqueza ambiental, sem nenhuma infraestrutura e totalmente desfavorável à urbanização.

O Poder Público, às margens do problema, tentou conter inicialmente a ocupação de forma violenta utilizando força policial (BARBOSA, 1983, A GAZETA, s/p) e posteriormente viabilizou a elaboração de planos e projetos para a região, que até hoje continua seu processo de expansão através das “invasões" e que carrega as cicatrizes da exclusão, figurando entre os dez bairros mais violentos 
da RMGV em 2016 e 2017, um dos vinte bairros mais perigosos para se morar na RMGV (MOURA; OLIVEIRA, 2016, A TRIBUNA, p.14); onde mais se mata (CARDOSO, 2017, s/p), onde facções criminosas competem pelo tráfico de drogas (NASCIMENTO, 2020); situação que existe há décadas (A GAZETA, 1998, p.19).

Localizado na Região Administrativa III denominada Grande Aribiri e formada por 21 bairros, o bairro Santa Rita de Cássia tem como bairros vizinhos Aribiri, Ataíde, Alecrim, Ilha de Conceição, Primeiro de Maio, Zumbi dos Palmares, dentre outros. Os mapas da figura 1 a seguir mostram o bairro Santa Rita localizado no contexto da Região Administrativa III, inserida no município de Vila Velha, localizado próximo à capital do estado do Espírito Santo. A figura 2 mostra a vista aérea do bairro inserido no contexto dos seus bairros vizinhos.

FIGURA 1 - MAPAS DO ESTADO DO ESPÍRITO SANTO, DOS MUNICÍPIOS DE VITÓRIA E VILA VELHA E DO BAIRRO SANTA RITA DE CÁSSIA INSERIDO NA REGIÃO ADMINISTRATIVA III.
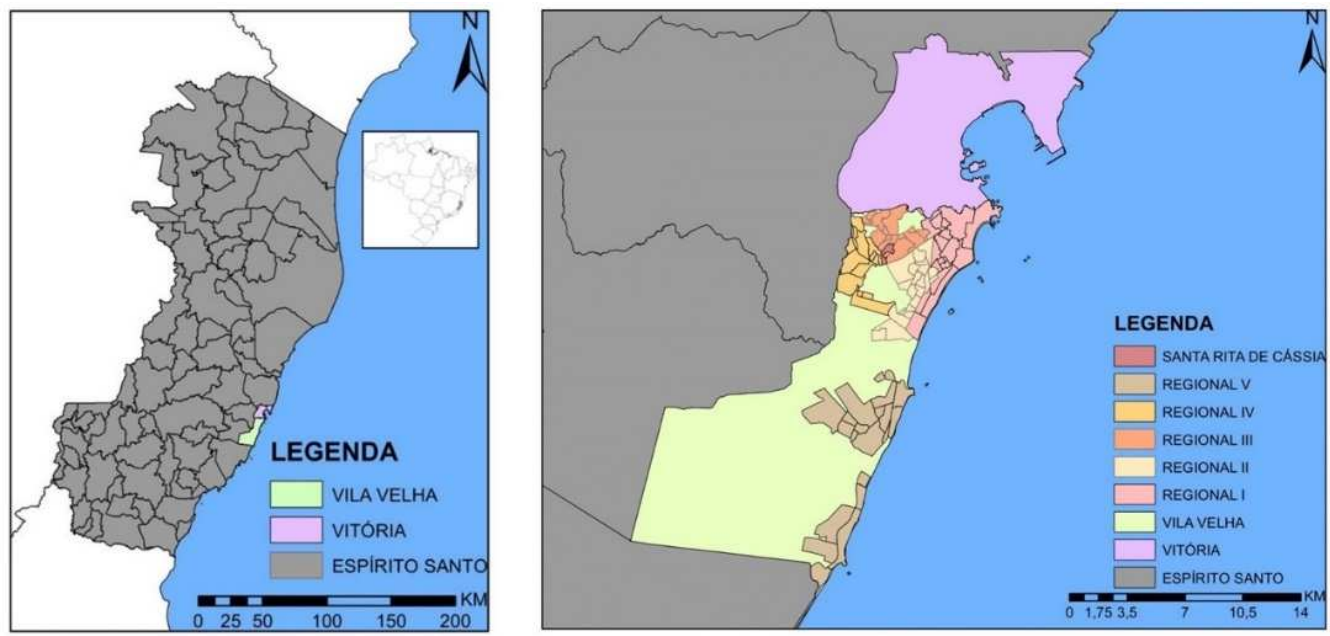

Fonte: Autoras, 2020.

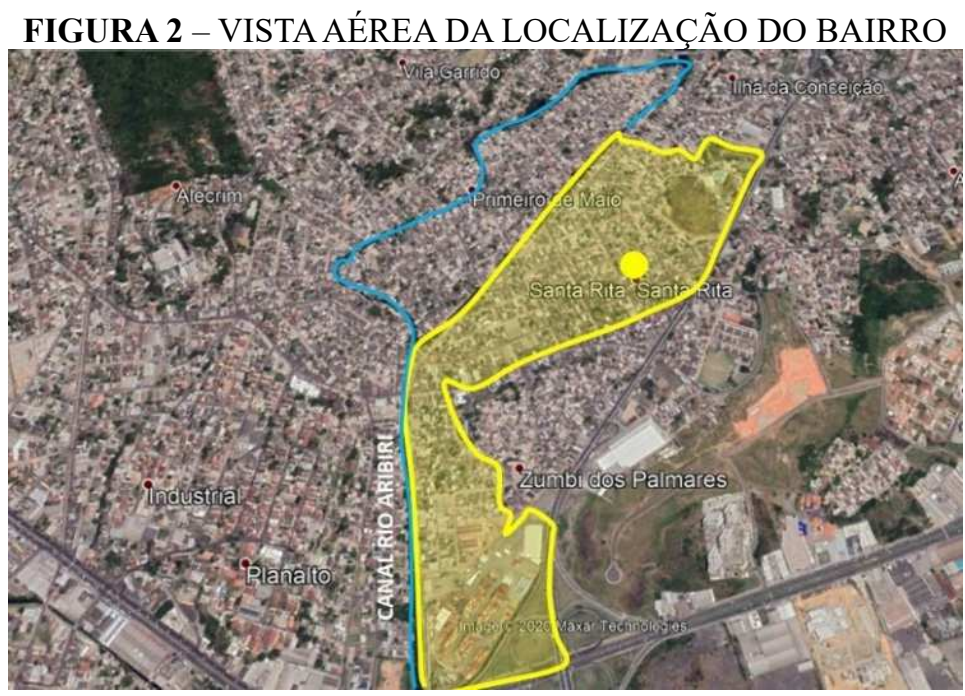

Fonte: Autoras, 2020. 
Denominado Ilha de Santa Rita na década de 1960, o bairro começou a ser formado em 1962 nas proximidades da Bacia do Rio Aribiri através da ocupação de famílias carentes que invadiram as áreas de mangue que conformavam a região. $\mathrm{O}$ bairro foi formado por migrantes vindos em sua maioria do interior do estado em busca de oportunidades de emprego nas indústrias e comércios. Os primeiros terrenos foram doados pela prefeitura às famílias pobres e outros começaram a ser vendidos por terceiros, assim como relatos colhidos em documentos do IJSN (1983, p. 6), que mostram a clara participação do poder público nas ocupações:

\begin{abstract}
Ao longo dos últimos 10 anos o poder público, para preservar áreas de interesse do setor imobiliário, promoveu informalmente a ocupação da Ilha de Ilha Santa Rita, utilizando-se dela, também, como um instrumento de cooptação política. Apesar de ser uma área da União (terreno de marinha) e estar a $0,70 \mathrm{~cm}$ abaixo da cota da maré máxima, a Prefeitura elaborou uma planta de loteamento com lotes de $300 \mathrm{~m}^{2}$, definição do futuro sistema viário e destinação de uma área para praça, promovendo a doação destes lotes à população invasora em potencial, e fornecia uma planta de situação que localizava o lote no "loteamento", como documento.
\end{abstract}

A situação acima é evidenciada pelo relato, em uma reportagem de jornal, de um dos primeiros moradores, senhor Cleto Severo, de 67 anos, que chegou ao bairro e construiu seu barraco em 1962 e descreve "que quase todos os lotes ocupados na região foram doados pelo ex-prefeito de Vila Velha, Américo Bernardes da Silveira" (A GAZETA, 1998, p. 19).

Em 1979 as migrações geradas pelas fortes enchentes que assolaram o ES trouxeram do interior um contingente populacional para a Ilha de Santa Rita. O loteamento inicial foi subdividido em lotes de $150 \mathrm{~m}^{2}$, restando pouco do traçado proposto originalmente. Por se localizar em uma região de mangue houve muitas dificuldades enfrentadas pelos moradores na ocupação, formada por palafitas e barracos de madeira, em meio à água, à lama e esgoto. Em relação à infraestrutura do bairro, havia muita precariedade. Não existia iluminação elétrica, água encanada nem coleta de lixo (A TRIBUNA, 2007, p. 9).

Segundo o IJSN (1981, p. 10) o aglomerado de Santa Rita era formado pelos bairros Alecrim, Santa Rita, Pedra dos Búzios, Capuaba, Vila Garrido, Ilha da Conceição e Ilha das Goiabeiras, com uma população de 30.184 habitantes, correspondendo à $14,8 \%$ da população do município de Vila Velha (203.498 habitantes) e 4,2\% da população da Grande Vitória (720.421 pessoas), concentrada em uma área de 178 hectares, de extrema precariedade, sem nenhuma infraestrutura urbana de esgoto, água, sistema viário e energia elétrica, convivendo com lixo e esgoto à céu aberto. 
Documento do IJSN (1981, p. 13) descreve a situação de precariedade e a participação do Poder Público Municipal na formação deste cenário ao utilizar lixo para aterrar o mangue e proporcionar o assentamento dos ocupantes:

\begin{abstract}
Somente a rede de valas do bairro Santa Rica é que teve seu traçado previamente definido. As demais, surgem e/ou desaparecem à medida que novas áreas vão sendo aterradas. Dos canais principais dos mangues não têm seus traçados respeitados nem mesmo pela Prefeitura de Vila Velha, que atualmente tem usado o aterro como lixo para recobrimento dos mesmos. Esse tipo de aterro é totalmente condenável para região, representando hoje sua maior fonte de poluição.
\end{abstract}

A montagem da figura 3 retrata a precariedade do bairro, com palafitas construídas sobre o mangue e crianças em meio ao lixão utilizado para aterrar o mangue. O lixão deixou o bairro somente em 1985.

FIGURA 3 - PRECARIEDADE DA OCUPAÇÃO DO BAIRRO EM 1978 E 1982.

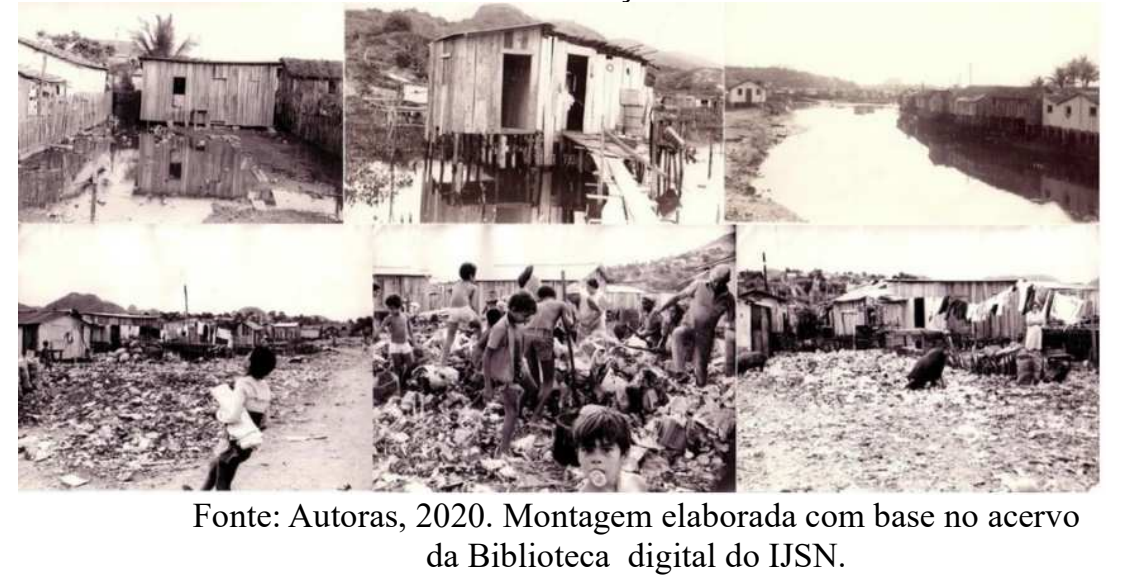

Santa Rita nasceu em meio ao lixo, sobre palafitas edificadas em um berçário ambiental, a Bacia do Rio Aribiri, que hoje está totalmente poluído. Em busca por onde morar, famílias pobres buscaram a terra que o mercado imobiliário não queria. Em 1983, Vila Velha já possuía 34 assentamentos subnormais, com mais de 120 mil habitantes (52\% da população municipal), sendo 40 mil pessoas no aglomerado de Santa Rita (IJSN, 1983, p. 3).

Nos últimos 60 anos, o bairro recebeu uma série de melhorias relacionadas à infraestrutura urbana. Na década de 1970 Santa Rita recebeu pavimentação e energia elétrica. Nas décadas seguintes os demais serviços básicos de água encanada, rede de esgoto e coleta de lixo foram implantados. Porém, a forma de produzir a habitação permaneceu a autoconstrução realizada pela população pobre.

Nos anos 70 havia rede elétrica e hidráulica em 50\% das moradias, além de uma linha de transporte coletivo que percorria a principal rua do bairro, conforme descrito no Projeto Piloto de Interesse Social para os Bairros Alecrim e Santa Rita de Cássia elaborado pelo IJSN em 1978. O 
projeto contemplava infraestrutura, urbanização e melhoria das habitações, objetivando o desenvolvimento socioeconômico da população local (IJSN, 1978).

$\mathrm{Na}$ década de 1980 foram realizados diversos estudos com propostas de intervenções nos aglomerados subnormais do estado, o que incluía Santa Rita. Somente nessa década foram elaborados quatro projetos: um em 1980, dois em 1983 e um em 1987.

Tais intervenções, assim como no projeto piloto de 1978, tinham como foco a infraestrutura (que apesar de representar um avanço em relação aos anos iniciais de Santa Rita não englobava o bairro inteiro até então) e a melhoria das habitações. Sobre isso, a proposta contida no Projeto de Urbanização da Ilha de Santa Rita de 1983 englobava "proposta de Habitação Popular para população de baixa renda da PMVV, utilizando-se tecnologias alternativas associadas ao trabalho comunitário", ou seja, o mutirão ou ajuda mútua (IJSN, 1983, p. 3).

Em 1983 a situação era de precariedade e pobreza extrema no bairro com 2023 pessoas alocadas em 600 famílias distribuídas em 600 domicílios, compostos por barracos de 1 a 5 cômodos que abrigavam em média 4,4 pessoas/barraco, que eram próprios (85\%), alugados (9\%) ou cedidos (6\%), com esgoto sendo lançado direto no mangue. Apenas 23,2\% dos moradores trabalhavam em subempregos ou na informalidade, sendo que $71,3 \%$ dos moradores não chegaram a concluir a $4^{\mathrm{a}}$ série. Destes, $20 \%$ eram analfabetos. Neste cenário, $48,18 \%$ da população pertenciam à faixa etária entre 0 a 14 anos; 7,73\% tinham entre 14 e 18 anos; 23,29\% entre 18 e 35 anos; 13,76\% entre 35 e 60 anos e 2,04\% acima de 60 anos. Portanto, a maioria eram crianças e adolescentes expostos à extrema situação de vulnerabilidade e miséria, sobre uma área alagável (IJSN, 1983, p. 7).

O projeto de Urbanização da Ilha de Santa Rita apresentado à população local em 1983, elaborado pelo governo do Estado em parceria com a prefeitura, contemplava quatro alternativas: aterro até à cota superior à maré e urbanização, aterro apenas do sistema viário e das áreas destinadas a equipamentos comunitários, melhoria de passarelas e realocação da população para uma nova área com construção de embriões para moradia e consequente eliminação da ilha, visando evitar sua reocupação (IJSN, 1983, p. 14).

Submetida à apreciação da associação dos moradores locais e posta em votação, a alternativa de aterro total, com algumas alterações, foi a escolhida e posta em prática parcialmente. O desenho urbano proposto sobre o aterro hidráulico com cota de $1,90 \mathrm{~m}$, realizado com argila do mangue, comtemplava a criação de quadras com 30 metros de larguras, contendo 1245 novos lotes residenciais e realocação de 912 barracos. Os novos lotes de $90 \mathrm{~m}^{2}$ com 6 metros de testada por 15 metros de 
fundos, seriam implantados sobre um traçado viário contendo vias principais de 6 metros de largura e vias secundárias de 4 metros "pavimentadas" com argila; além da construção de 3 pontes sobre os canais e de um local destinado à praça pública. Sobre a infraestrutura, foi proposta soluções de esgotamento sanitário para fossas com lançamento nos canais (IJSN, 1983, p. 17).

A análise dos documentos demostra que a construção de moradias ficou em segundo plano, sendo a posse da terra sempre a alternativa, independente da forma de morar, seja um barraco ou palafita. A política habitacional não aparece durante o contexto histórico.

Na década de 1990 a COHAB - ES propôs, em parceria com o governo federal, obras de melhorias em infraestrutura: drenagem pluvial em 10 quilômetros de ruas, revestimento de alguns canais com pedras para conter a água, construção de novas galerias de concreto armado, 10 quilômetros para drenagem do esgoto de casas e ruas e pavimentação de 30 quilômetros de ruas (DENADAY, 1991, A TRIBUNA, s/p).

Em síntese, a pesquisa identificou cinco propostas de projetos para Santa Rita, elaborados pelo Estado em parceria com os entes municipal e federal. Percebe-se que os projetos buscavam responder às carências de infraestrutura de esgoto, água, sistema viário, drenagem e outras. A questão da moradia, com a construção de unidades ou melhorias habitacionais ficou em segundo plano ou não foi reivindicada pela população. O PROMORAR (Programa de Moradia para Erradicação das Habitações Sub-Humanas) do BNH não contemplou a região.

Sobre a intervenção pública na questão da moradia no município de Vila Velha, no período de vigência do BNH no estado (1968 a 1986) foram construídos pela Companhia Habitacional do Estado (COHAB-ES) 10 empreendimentos habitacionais no município, totalizando 3.592 unidades, o que corresponde a 14\% de toda produção para a Região da Grande Vitória. De 1987 a 2002, as intervenções foram direcionadas à urbanização, regularização fundiária e reassentamento em assentamentos precários, totalizando 8.667 famílias atendidas pelo município, com iniciativas em parceria com o Poder Público Estadual e Federal, através dos programas habitacionais Pró-Moradia e Habitar Brasil (VILA VELHA, 2015, p.122).

Nestas intervenções de urbanização de aglomerados urbanos, 8 mil famílias foram atendidas com infraestrutura básica em Santa Rita em 1993. Para o bairro, no período de 2003 a 2103, as ações com recursos federais, via programa PPI-Favelas/PAC, viabilizaram a construção de 56 unidades habitacionais na tipologia sobrado em fita de dois pavimentos, denominado empreendimento Residencial Zumbi dos Palmares, localizado na Baixada do Rio Aribiri e ocupando uma área de terra 
estimada de $4.000 \mathrm{~m}^{2}$ com a sua implantação próxima à Rodovia Carlos Lindemberg, importante via que liga Vila Velha à Vitória. De 2010 a 2013 não houve nenhum investimento em habitação social no município (VILA VELHA, 2015, p.122).

No âmbito da discussão da não priorização da moradia pelo Poder Público, de acordo com o IJSN (2019) baseado em dados da Fundação João Pinheiro, Vila Velha possui 7.258 famílias (9,75\%) de um total de 37.949 famílias da $\operatorname{RMGV}$ (50,97\%), figurando em segundo lugar no déficit habitacional do Espírito Santo, que possui 74.454 famílias em situação déficit habitacional inscritas no Cadastro Único para programas sociais.

Importante destacar, que conforme verificado pelas autoras nos documentos do Plano Local de Habitação de Interesse Social do Município de Vila Velha (VILA VELHA, 2015, p. 46) a demanda estimada de unidades habitacionais para um cenário até 2030 é de 28.670 novas unidades, consideradas para as faixas de renda de $1 / 2$ a 3 salários mínimos per capita. Quanto à estimativa de terra necessária para atender à construção destas novas unidades, foram estimados cerca de 155 hectares de terra urbanizada no município, o que remete a uma expectativa de reserva anual mínima de terra correspondente a 5,2 hectares para o atendimento da demanda atual e futura, considerando um cenário até 2030.

Buscar manter suas áreas públicas vazias para atingir essas metas e negociar novas áreas com empreendedores privados são estratégias delineadas pelo ente municipal, mas que não são simples, tendo em vista a valorização e disputa pela terra, realizada pelo mercado imobiliário privado e pelos excluídos das políticas habitacionais, que continuam a reivindicar o direito à terra através das "invasões", o que veremos a seguir.

\section{BAIRRO SANTA RITA DE CÁSSIA: AS OCUPAÇÕES DE TERRAS CONTINUAM}

Após as melhorias urbanas realizadas nas últimas três décadas, o bairro Santa Rita, constituído por uma extensa área plana de $210 \mathrm{mil} \mathrm{m}^{2}$ onde se distribuem 5.526 habitantes em 1.793 domicílios particulares permanentemente ocupados (desses, 82,8\% são próprios); encontra-se em estágio de consolidação urbana quanto aos serviços públicos de infraestrutura e acesso a serviços coletivos. $\mathrm{O}$ bairro possui rede de água, esgoto, energia elétrica, coleta de lixo, ruas pavimentadas, sistema de drenagem, cinco escolas públicas, uma Unidade Básica de Saúde, um campo de futebol e uma praça (PMVV, 2016). Apesar da maioria da população local ter moradia própria, os moradores possuem renda baixa, sendo a 10 ${ }^{\mathrm{a}}$ menor da Região Administrativa III (PMVV, 2016). 
Quanto à forma de ocupação e uso do solo, a função residencial predomina, distribuída sobre um traçado ortogonal de quadras, consequência do acerto topográfico realizado pelo Poder Público. Por outro lado, a porção sul do bairro, possui um traçado irregular, resultado da expansão da ocupação espontânea que ainda continua evoluindo e formou um assentamento informal precário no entorno do Residencial Zumbi dos Palmares, cuja área de terreno remanescente foi ocupada por famílias pobres. Desta forma, a modalidade de produção do espaço através das ocupações de terras continua em Santa Rita (figura 4).

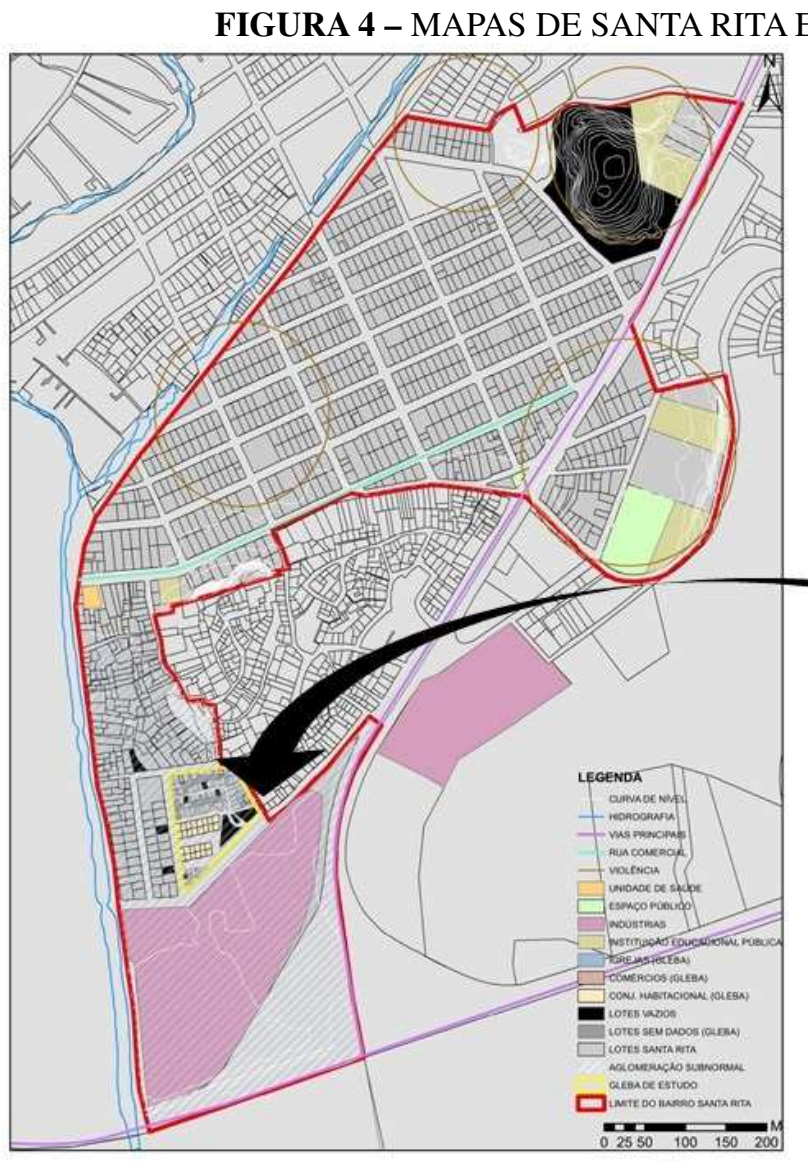

SANTA RITA - MAPA DE USO E OCUPAÇÃO

Fonte: Autoras, 2020.

A visita de campo ao assentamento, realizada por três pesquisadores e sete alunos de graduação e mestrado, permitiu coletar dados que possibilitaram montar um quadro analítico sobre a forma de ocupação e uso da gleba, sobre as características físicas das habitações autoconstruídas e as ações do poder público para a área. 
O mapa da figura 4 demonstra a espacialização destes dados, onde foram identificadas 76 unidades de terreno, sobre os quais foram implantados 31 barracos de madeira, 26 casas em alvenaria, 11 casas em construção, 3 igrejas evangélicas e um bar. Ainda existem 5 lotes vazios mas que estão protegidos por cercas, o que configura e demonstra a possibilidade de propriedade privada informal estabelecida.

A ocupação espontânea que vem ocorrendo desde 2016 sobre o terreno de propriedade pública, gerou um assentamento precário caracterizado pela ausência de serviços básicos e pela autoconstrução da moradia, processo utilizado pelos ocupantes da gleba, onde se identifica a baixa qualidade construtiva das unidades habitacionais, edificadas de forma improvisada, com materiais de baixa qualidade, sem assessoria técnica profissional e sem financiamento do poder público.

A figura 5 retrata a evolução do fenômeno da ocupação da área, conformada por um perímetro de 404,85 metros e quase 1 hectare, que deveria receber a implantação da $2^{\mathrm{a}}$ etapa de um conjunto habitacional destinado à moradia social descrito no Plano Local de Habitação de Interesse Social PLHIS (PMVV, 2015, p.64) como ação estratégia no âmbito da questão habitacional a ser viabilizada pelo ente municipal via Programa PPI-Favelas/PAC Grande Santa Rita, conforme investigação realizada no documento pelos autores deste trabalho.

Verifica-se que em 2015, a etapa 1 do empreendimento, já finalizado ocupava parte do terreno, formado por duas glebas públicas inicialmente, que em 2016 passou a ser "invadido" de forma gradual por famílias que dividiram a terra de forma desordenada em 76 unidades, distribuídas em uma área aproximada de 0,5 hectare, o que configura uma área de terreno médio de $65 \mathrm{~m}^{2}$ por família.

Os ocupantes passaram a pressionar a prefeitura por melhorias no local: construção de uma praça, regularização fundiária, intervenção no traçado viário e instalação da rede de esgoto. A única reivindicação atendida são os dois últimos itens. O ente municipal iniciou em 2019 obras de reordenamento do traçado viário, com implantação do sistema de drenagem e esgoto, o que implica na demolição de partes de algumas moradias autoconstruídas, proposta aceita pelos ocupantes na perspectiva de que as melhorias tragam na sequência a posse da terra, viabilizada pela regularização fundiária, não prometida pelo representante do município, que busca tratar a ocupação de forma pacífica, sem implementar qualquer iniciativa de remoção, diferente das décadas anteriores. 
FIGURA 5 - EVOLUÇÃO DO FENÔMENO DA OCUPAÇÃO DA ÁREA

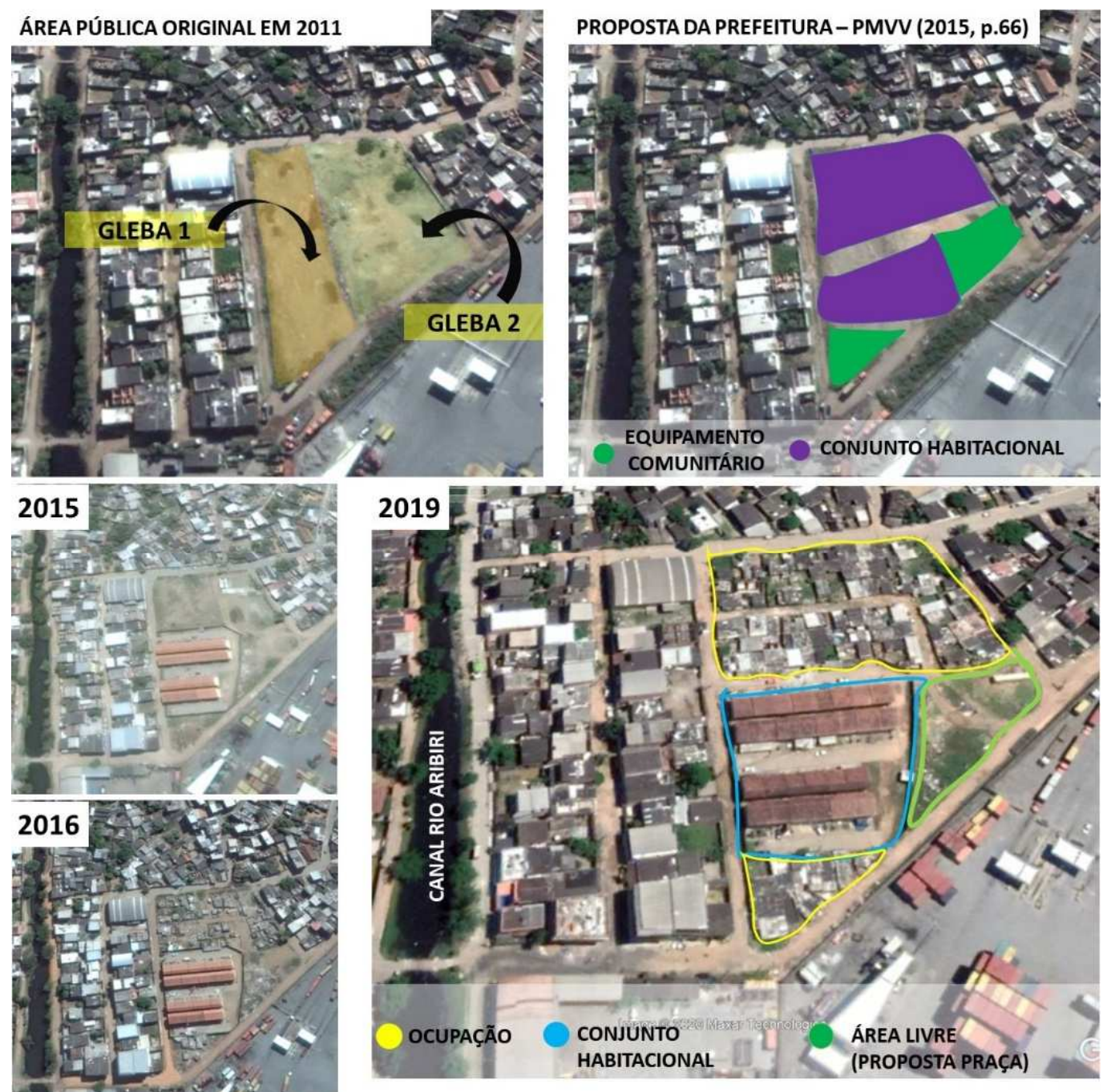

Fonte: Autoras, 2020.

Para conter a expansão pela ocupação da área livre ao lado do conjunto habitacional, reivindicada como uma praça pela comunidade local, a prefeitura instalou tapumes e o canteiro de obras para isolá-la e impedir que novas investidas ocorram contra o terreno em disputa (figura 6).

FIGURA 6 - INTERVENÇÕES DO PODER PÚBLICO NA OCUPAÇÃO E ISOLAMENTO DA ÁREA

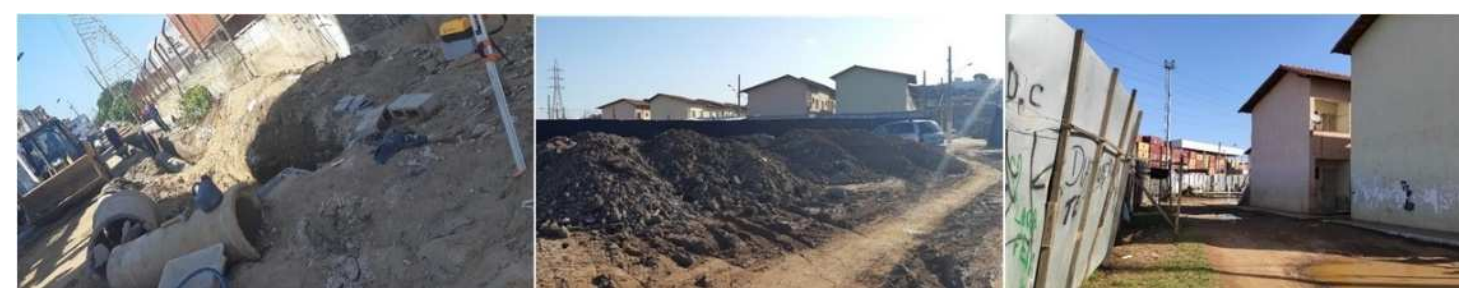

Fonte: Autoras, 2020. 
É importante analisar que as "invasões” de terras públicas representam maior possibilidade de permanência e consolidação do assentamento, uma vez que os embates com proprietários fundiários privados são maiores devido à condição da propriedade privada ser um direito civil estabelecido, que garante aos proprietários fundiários maiores garantias no caso da desocupação. Para as terras públicas isso se processa de forma diferente, com discussões que imputam ao ente público a responsabilidade em atender as famílias com políticas sociais efetivas. Nota-se que os serviços públicos, parcialmente implantados, estão chegando desvinculados da política fundiária e habitacional. A autoconstrução é a forma de produção da moradia aceita por todos, que reivindicam infraestrutura e posse da terra, mas não a produção pública da habitação.

As moradias autoconstruídas estão em diferentes processos de desenvolvimento (figura 7): barracos em madeira de baixa qualidade, casas de alvenaria em tijolos aparentes, casas sem revestimento de piso e até mesmo, moradias com chão de terra batida. Algumas, com a presença de banheiros ou sanitários improvisados, sem esgotamento sanitário adequado. Por outro lado, verificase que há ocupantes que já realizaram melhorias em suas unidades habitacionais, o que demonstra que existe a confiança de permanência do assentamento e sua consequente consolidação, com a valorização fundiária advinda das melhorias em curso, representadas pelos serviços urbanos.

\section{FIGURA 7 - DIFERENTES ESTÁGIOS DA AUTOCONSTRUÇÃO - DO BARRACO À CASA DE ALVENARIA}

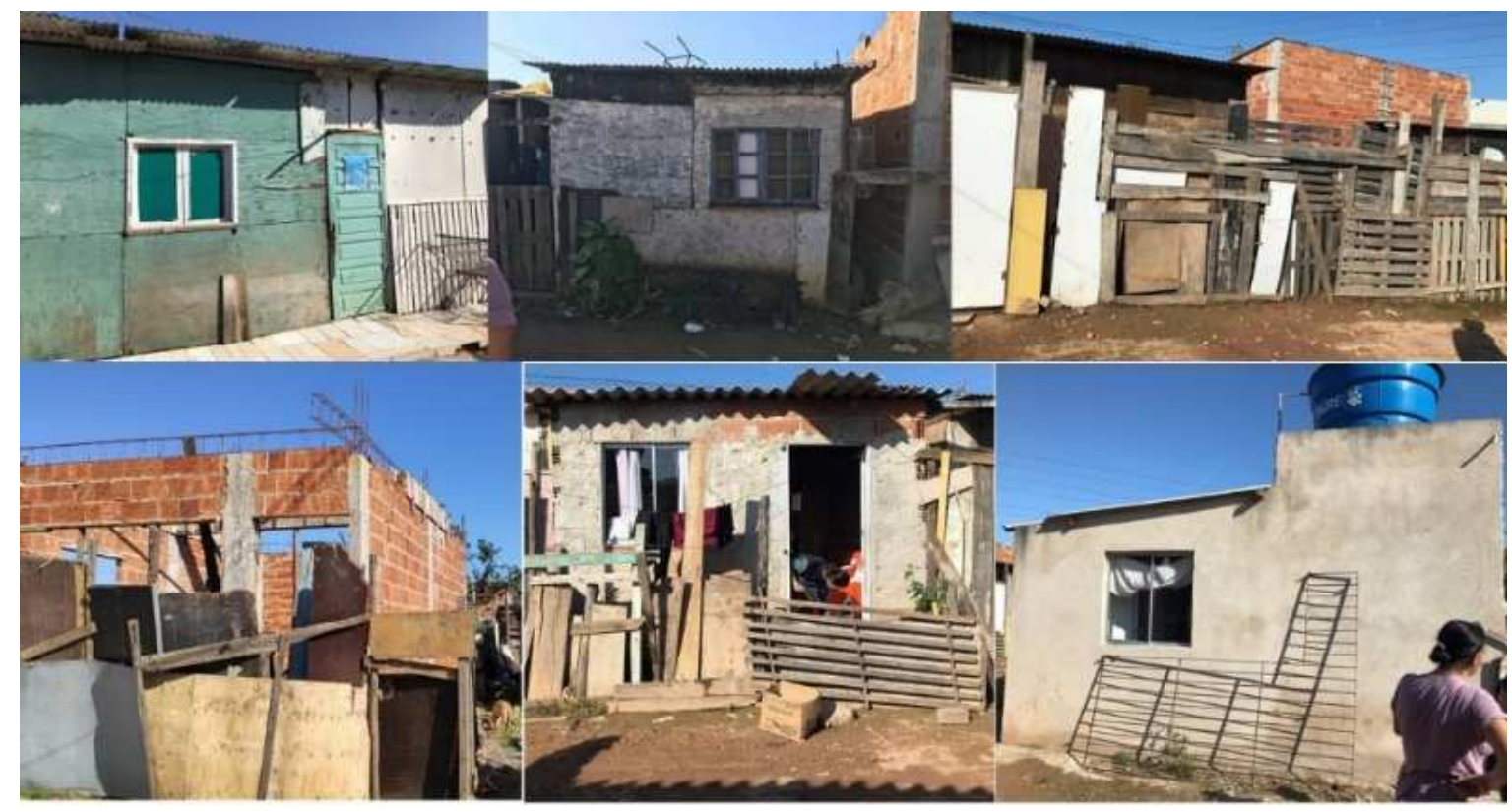

Fonte: Autoras, 2020. 
Quanto ao parcelamento do solo, verifica-se uma divisão informal de lotes, com moradias implantadas em fundos de terrenos, sem acesso frontal para as vias, realizado através de becos, o que dificulta ainda mais a regularização fundiária que pode vir a ser realizada pelo ente municipal, tendo em vista o número de "proprietários informais" dentro do mesmo lote.

Quanto ao uso e ocupação do solo, nota-se o surgimento de comércios informais para a venda de gás e carvão, além de um estabelecimento para consumo de bebidas e jogo de sinuca. Despertou o olhar dos pesquisadores a presença da igreja evangélica, duas em construção e outra já em funcionamento, o que pode representar a expansão de um agente de forte influência no território, o que não é o foco deste artigo ampliar a discussão.

\section{CONCLUSÃO}

Em 1977 o cenário era de pobreza intensa na RGV, expresso pelo seu espaço urbano formado por assentamentos informais com moradias precárias, onde 262.000 pessoas carentes (47\% da população) viviam em 82 ocupações sobre mangues, baixadas, encostas e morros (IJSN, 1980). Neste contexto, formou-se o bairro Santa Rita, que abrigou uma população pobre em habitações precárias sobre o mangue, que foi aterrado com lixo e argila da bacia do Canal do Aribiri, rio que sofreu com os impactos da ocupação desordenada e atualmente encontra-se totalmente poluído de esgoto.

A história da formação do bairro Santa Rita, que continua sendo ocupado por famílias excluídas das políticas habitacionais, reproduz o que aconteceu em muitas cidades brasileiras onde os assentamentos precários surgiram a partir da ausência do poder público ou até mesmo sob sua conivência.

A informalidade no morar é a estratégia de sobrevivência que estas famílias buscam, que depende do acesso à terra para ser realizada. Portanto, a questão fundiária, o acesso à terra é a matriz discursiva que deve nortear qualquer proposta para a questão habitacional. O que se compreende com a análise do assentamento precário investigado é que a moradia formal produzida pelo ente municipal não faz parte dos discursos de reivindicação dos ocupantes da área, sendo a propriedade da terra a prioridade. Do outro lado, o Poder Público atende com a manutenção do assentamento e investe em serviços de infraestrutura, distante da sua responsabilidade na provisão da moradia social. Ciclo que se repete por todo país há décadas. 


\section{REFERÊNCIAS}

A GAZETA. Violência aterroriza os moradores de Santa Rita. Vitória, 08 jul. 1998. Disponível em: http://www.ijsn.es.gov.br/bibliotecaonline. Acesso em: 10 mar. 2020.

A TRIBUNA. Santa Rita Surgiu de Manguezal. Vitória, 28 FE. 2007. Disponível em: http://www.ijsn.es.gov.br/bibliotecaonline/Record/341097. Acesso em: 25 mar. 2020.

BARBOSA, T. Polícia expulsa os invasores de Santa Rita. A Gazeta, Vitória, 18 jan. 1983, s/p. Disponível em: http://www.ijsn.es.gov.br/bibliotecaonline. Acesso em: 10 set. 2019.

BONDUKI, N. Crise de habitação e luta pela moradia no pós-guerra. In: ANT, Clara. et al. (Org.). As lutas sociais e a cidade: São Paulo, passado e presente. Rio de Janeiro: Paz e Terra, 1994. Capítulo 4, p. 113-144.

CARDOSO, J. Vinte bairros onde mais se mata na Grande Vitória. Tribunaonline, Vitória, 02 out. 2017. Disponível em: https://tribunaonline.com.br/vinte-bairros-onde-mais-se-mata-na-grandevitoria. Acesso em: 25 fev. 2020.

CORRÊA, R. L. O espaço urbano. São Paulo: Editora Ática, 1989. 95p.

DENADAY, C. Urbanização de Santa Rita vai beneficiar 30 mil pessoas. A Tribuna, Vitória, 05 jan. 1991. Disponível em: http://www.ijsn.es.gov.br/bibliotecaonline/Record/341100. Acesso em: 25 mar. 2020.

IJSN. Projeto Piloto de Interesse Social para os Bairros Alecrim e Santa Rita de Cássia. Vitória/ES, 1978. Disponível em: http://www.ijsn.es.gov.br/bibliotecaonline/Record/5129. Acesso em: 10 fev. 2020.

. Programa CPM/BIRD - Subprojeto Vitória: perfil da cidade, estratégia de intervenção. Governo do Estado do Espírito Santo. Vitória, 1980. Disponível em: http://www.ijsn.es.gov.br/ConteudoDigital/20121205_ij00182_projetocpm_bird_v3.pdf. Acesso em: 10 fev. 2020.

. Projeto Especial Cidades de Porte Médio - Subprojeto AUV: Elaboração de Estudos da Bacia do Rio Aribiri. Volume 2. Vila Velha/ES, 1983. Disponível em: $<$ http://www.ijsn.es.gov.br/bibliotecaonline/Record/5118. Acesso em: 03 fev 2020.

. Urbanização da Ilha de Santa Rita: Proposta de intervenção integrada no aglomerado de Santa Rita. Vila Velha/ES, 1983. Disponível em: http://www.ijsn.es.gov.br/bibliotecaonline/Record/5272. Acesso em: 03 fev 2020.

Plano Emergencial de Habitação - Grande Vitória. Vitória/ES, 1987. Disponível em: http://www.ijsn.es.gov.br/bibliotecaonline/Record/4930. Acesso em: 03 fev. 2020.

. Estudo sobre ocupação irregular de terra na Grande Vitória. Vitória/ES, 1995. Disponível em: http://www.ijsn.es.gov.br/bibliotecaonline/Record/4564. Acesso em: 10 fev. 2020.

Ocupação Social Santa Rita. Vitória/ES, 2017. Disponível em: http://www.ijsn.es.gov.br/bibliotecaonline/Record/341472. Acesso em: 10 fev. 2020.

Déficit Habitacional no Espírito Santo com base no CadÚnico. Vitória/ES, 2019. Disponível em: http://www.ijsn.es.gov.br/component/attachments/download/6768. Acesso em: 20 mar. 2020.

KOWARICK, L. Escritos Urbanos. São Paulo: Ed. 34, 2000. 144p. 
. Viver em Risco: sobre a vulnerabilidade socioeconômica e civil. São Paulo: Editora 34, 2009. 320p.

LOURENÇO, T. C. B. Cidade ocupada. 2014. Volume I. Dissertação de Mestrado (Núcleo de Pósgraduação em Arquitetura e Urbanismo), Universidade Federal de Minas Gerais, Belo Horizonte, 2014.

MOURA, W.; OLIVEIRA L. Vinte bairros mais perigosos para morar. A Tribuna, Vitória, 22 mar. 2016. Polícia, p. 14.01 Disponível http://www.ijsn.es.gov.br/ConteudoDigital/20160408_aj24407_violencia_bairros.pdf. Acesso em: 10 out. 2019.

NASCIMENTO, T. Traficantes trocam tiros com guardas municipais de Vila Velha na Faixa de Gaza. Tribunaonline, Vitória, 23 mar. 2020. Disponível em: https://tribunaonline.com.br/traficantestrocam-tiros-com-guardas-municipais-de-vila-velha-na-faixa-de-gaza. Acesso em: 25 fev. 2020.

SANTOS, Milton. A urbanização brasileira. São Paulo: Editora Hucitec, 2018. 176p.

SIQUEIRA, M. da P. S. Industrialização e Empobrecimento Urbano - o caso da Grande Vitória. Editora: Grafitusa, 2010. 164p.

VILA VELHA. Plano Local de Habitação de Interesse Social: Diagnóstico v 1. Vila Velha/ES, 2015.

. Plano Local de Habitação de Interesse Social: Estratégias de ação. Vila Velha/ES, 2015.

. Perfil Socioeconômico por bairros. Vila Velha/ES, 2016. Disponível em: https://www.vilavelha.es.gov.br/. Acesso em: 10 abr. 2020.

WERNA et al. Plauralismo na Habitação (baseado nos resultados do Projeto "O novo papel do Estado na oferta de habitação: parceria entre agentes públicos e não-públicos”: convênio 63.96.0737Finep). São Paulo: Annablume, 2001. 300p. 